At higher deformations more sub-lines are found in each cluster, while at very low deformations the zones are widely spaced at all temperatures and contain only one of the elementary slip-lines.

Thus the progress of increasing deformation is different at different temperatures : first, at all temperatures, one-line zones are formed at small deformations, and increasing deformation creates new zones until a minimum spacing depending on tem. perature in the manner given above is reached. Thereafter increasing deformation results in increasing multiplicity in the zones.

The curved form usually found in slip-zones formed at high temperatures means that slip can be transferred from one of the elementary slip-planes to another parallel one by means of a third, intersecting, slip-plane; the direction of slip being the same in both systems. Thus, elementary slip-lines may appear to be stepped, and this means that the elementary slip-planes are enabled to interweave at high temperatures and even at room temperature, although the phenomenon has not been observed at liquid-air temperature. A similar effect has been found in brass by Maddin, Mathewson and Hibbard ${ }^{3}$, but here the scale was large enough to be visible in the light microscope.

The thickness of the elementary glide lamellæ is more variable than their relative displacement; neither does it appear to be directly related to temperature. The most common thickness is about $200 \mathrm{~A}$., but values up to $800 \mathrm{~A}$. are found, particularly at the higher temperatures. The origin of the lamellæ is uncertain ; but it is interesting to note that studies of shadowed replicas of unetched electro-polished aluminium surfaces reveal a furrow-like structurerather like the thermal etch structure studied on the surface of silver by Chalmers, King and Shuttleworth ${ }^{4}$, but sometimes more irregular, depending on the crystallographic nature of the surface and the direction of shadowing. The observed size of this furrow structure is of the same order as the observed thickness of the elementary slip lamellæ and, in some cases, has the same direction.

Cavendish Laboratory,

Arthur F. Brown

Cambridge.

May 2.

${ }^{1}$ Heidenreich, K. D., and Shockley, W., J. App. Phys., 18, 1029 (1947). 2 Lacombe, P., and Beaujard, I., J. Inst. Metals, 74, I (1947).

s Maddin, R., Mathewson, C. H., and Hibbard, W. R., jun., Metals Tech., T.P. 2331 (February 1948).

- Chalmers, B., King, R., and Shuttleworth, H., Proc. Roy. Soc., A, 193, 465 (1948)

\section{Occurrence of Sepiolite in the Lizard Serpentines}

DURING an excursion to Lizard Head (Cornwall), we examined in some detail the exposures of serpentine at the water-edge. At a point situated about 500 metres south-east of Kynance Cove Hotel, our attention was attracted by the presence of numerous white veinlets, standing out against the dark colour of the rock. One of them, almost vertical, about $5 \mathrm{~cm}$. wide, shows on its upper face a thin layer of a fibrous mineral. The chemical analysis, differential thermal curve, and graph of weight-loss as a function of temperature for this mineral are similar to those obtained with Ampandrandava sepiolite. The few differences observed can be attributed to the presence of calcite associated with the Kynance Cove mineral.
X-ray diagrams show the complete identity of the two silicates. We may emphasize that in both cases a fibre diagram can be obtained by using suitably chosen fragments. The Kynance Cove mineral is thus a sepiolite; an identification which is confirmed by microscopic examination, which shows the follow. ing optical properties: the fibres have straight extinction with positive elongation; $\gamma=\mathbf{1 . 5 2}$; biaxial negative with small axial angle. This method also establishes the fact that the sepiolite has been formed after the calcite, which fills the larger part of the vein. The silicate fibres surround the grains of calcite, which are rounded off at the contact as if they had been corroded during the formation of the sepiolite.

This allows the conclusion to be drawn that the sepiolite, the most recent mineral of the series, is a secondary product resulting from the alteration of the encasing serpentine.

Our thanks are due to Dr. Clark and Dr. Parker, of English Clays Lovering Pochin and Co., Ltd., St. Austell, who helped in arranging the excursion, and to Dr. MacEwan (Rothamsted Experimental Station), who translated this note into English.

\section{Muséum National d'Histoire Naturelle,}

\section{S. CATLlikre}

Paris.

\section{S. Hษ́NIN}

Centre National de Recherches Agronomiques, Versailles.

\section{A Saline Agglutinating Kell Antibody}

Three examples of anti-Kell are known ${ }^{1}$; but all are of the incomplete variety necessitating the use of Coombs's reagent to develop their action. The serum here reported is the first saline agglutinating anti-Kell discovered.

It was found in a multiparous woman who had been delivered of a macerated, stillborn fotus. She was Group $O, R h$ positive, genotype $C D e / c D E, M, P$, Lewis negative, whereas her husband was Group $B$, $R h$ positive, genotype $C D e / C D e, M, N, p$, Lewis positive. Her serum contained an antibody, active in saline at $37^{\circ} \mathrm{C}$. with a titre of 4 , not related to the $A B O$, Rhesus, $M N S, P$, Lewis and Lutheran systems, and agglutinating Kell positive cells. Unfortunately, no blood was sent from the macerated foetus.

Race $^{2}$ has described the Kell antigen, and it would appear to be related to hrmolytic disease of the newborn, as in the first case described ${ }^{3}$ the child showed clinical signs and symptoms of the disease, with a positive Coombs's test, and responded to transfusion therapy, whereas the present case terminated in a macerated foetus.

The serum is active in albumen at $37^{\circ} \mathrm{C}$., is destroyed by heating at $70^{\circ} \mathrm{C}$. for $10 \mathrm{~min}$. and does not contain an incomplete antibody demonstrable by Coombs's reagent after heat treatment.

Tests with this serum against 566 unselected $O$ bloods shows the Kell antigen to occur in $7 \cdot 2$ per cent of English people.

\section{National Blood Transfusion Service, \\ Sheffield.}

I. Dunsford

1 Mourant, A, E., personal communication.

2 Race, R. R., Brit. Med. Bull., 192 (1946). ${ }^{3}$ Coombs. R. R. A., Mourant, A. E.: and Race, R. R., Lancet, i, 264 